\title{
MODERN FINANCE: A CATALYST FOR TRULY MODERN AGRICULTURE
}

\author{
MARGHERITA MORI \\ Professor in Financial Markets and Institutions, University of L'Aquila \\ Department of Industrial and Information Engineering, and of Economics \\ Via Mezzanotte, Località Acquasanta - 67100 L'Aquila, Italy \\ margherita.mori@univaq.it
}

\begin{abstract}
This paper aims at investigating the crucial role that the three pillars of the financial system - i.e. financial markets, products and institutions - are likely to play in order to speed up the process of modernization in agriculture, especially in agri-food chains. Four main areas of interest can be identified that consist of sustainable, inclusive, blended and rural finance, and that embody a set of strategic tools: their support to the agricultural sector ranges from its most traditional side to unprecedented forward steps, such as those pertaining to novel foods and to farming on Mars. While innovation allows for progress both in the financial industry and in agribusiness, glocal co-opetitive challenges surface from what can be found at the crossroads: a growing concern for sustainability issues is just an example, which leads to emphasize the 17 Sustainable Development Goals and the underlying generation pact. Focusing on finance, this is a qualitative research that draws upon empirical evidence and success stories; a framework for analysis is outlined, in an attempt at promoting rural finance as a specialized discipline from a theoretical point of view and a peculiar market segment for operating purposes, with relevant sub-sets such as agricultural finance, agricultural value chain finance and agricultural microfinance. Conclusions encompass recommendations that unveil academic implications; supporting arguments stem from - among others - the widely recognized need for upgrading financial education and literacy, especially in rural areas and even within the context of lifelong learning.
\end{abstract}

Keywords: blended finance, financial education, financial inclusion, rural finance, sustainable finance

\section{INTRODUCTION}

The research gap at the crossroads between financial innovation and innovation in agriculture is the main focus of this paper; it takes inspiration from the fallacies in the financial system that prevent it to adequately satisfy the needs of a large share of the world population and especially of smallholder farmers, who are mostly underbanked; as a consequence, valuable efforts aimed at making of agriculture a truly modern market segment run the risk of being vanished. Within this framework, what sounds especially appealing is the pursuit of the 17 Sustainable Development Goals (SDGs) that were adopted by the United Nations in 2015, upon setting the "2030 Agenda", and that cover challenging issues, such as ending poverty and hunger, responding to climate change, sustaining natural resources, as well as promoting sustainable agriculture and financial inclusion (UN, 2015).

Looking at finance, it is generally acknowledged as vital to help the real sphere of the economy move forward and persistent attention tends to be devoted to the primary sector, with agriculture spearheading the priority list. Undisputed evidence exists on rapid and significant changes occurred in the financial arena over the last few decades, due to many factors, such as technological progress and globalization: new financial products, markets and institutions have been allowed to proliferate, though banks and their services continue to play a prominent role in general terms; by contrast, according to reliable estimates (DEMIRGUC-KUNT ET AL., 2015), two billions adults - more than half of those who work in the world - should be labelled as unbanked, as they do not even hold a bank account, and much room remains for advancements particularly in rural areas. 
On the other side, agriculture can be still depicted as a traditional sector, in spite of the fact that the art of 'doing' sustainable innovation has gained momentum. Success stories abound in related market segments too: a recent example to follow - for production and distribution purposes - is the recourse to supermarket aisles that are reserved to products free of plastic packaging, as a way to join the global fight against pollution; they are supposed to symbolize the future of food retailing (TAYLOR, 2018).

Therefore, the analysis is designed to draw upon the evolutionary scenario of both the financial industry and the agricultural sector and the discussion revolves around how the former can best support the latter. It is not only a matter of replicating positive experiences but also of carrying out unprecedented activities, such as those that refer to novel foods and simulated "Martian gardens": the current modern farming paradigm has many techniques and practices that are important to maintain but innovating is a must, not only in agriculture; the same holds true for the financial system that should be even called to pursue its modernization as a precondition for the evolution of other industries, being money a scarce resource and innovation a risky, capital intensive process.

\section{MATERIAL AND METHOD}

In sight of reaching the proposed objective, the starting point can be identified with defining most relevant concepts, including modern finance and modern agriculture; the next step is intended to grant due weight to the relationship between them, that lies at the heart of the above mentioned research gap. Moreover, useful insights can be gained by scrutinizing the implications in terms of sustainability, which leads to address environmental and social issues with regard to both of the industries under investigation.

From a methodological perspective, this is an explorative study; a case-study research method tends to be privileged, as it seems most suitable to collect qualitative data and allows for flexibility. At the same time, the chosen approach has been forged in order to properly combine the local and global perspectives, as suggested by the wider and wider endorsement of the glocal philosophy, and to join the search for the appropriate mix of competition and cooperation, in line with the co-opetitive vision.

Conclusions encompass key messages and recommendations for policy interventions, as well as for further research and development. The rationale behind them features best practices that might be usefully disseminated, to the benefit of both the financial and the agricultural sectors, with related market segments too being involved; academic challenges also surface, in the light of the need for financial education, literacy and competence, as well as of the discipline status that rural finance deserves.

\section{RESULTS AND DISCUSSION}

Based on extensive and in-depth analysis - on most recent literature, pertaining legislation and institutional websites - it can be argued that four major areas provide ground for discussion and promise to generate encouraging results, thus paving the way to realistic solutions and guidelines for practical applications, as follows:

\section{Sustainable finance}

In line with the post-2015 development agenda, truly modern agriculture should satisfy strategic requirements for sustainability that - as pointed out by the Food and Agriculture Organization of the United Nations - imply an efficient use of resources, environmental 
protection, healthy ecosystems and responsible governance mechanisms, to mention just a few requirements (FAO, 2014). In turn, sustainable agriculture should rely on sustainable finance: to summarize, it consists of "the provision of finance to investments taking into account environmental, social and governance considerations" (Sustainable Finance, n.d.). Environmental considerations have to do with the strong green finance component that can support a sustainable growth path, as shown by the move to re-orient banking according to sustainability indexes and particularly to promote responsible lending; governance considerations are motivated by an increasing awareness of the risks that may affect the sustainability of the financial industry and are closely tied to the adoption of appropriate mitigation strategies. It is not a case that the need has been recently recognized to provide farmers, agri-food operators and rural entrepreneurs with the full range of financial possibilities existing under the European Agricultural Fund for Rural Development, in sight of building a farming and food sector which is fully in tune with the $21^{\text {st }}$ century, with a strong emphasis on sustainability, as well as on innovation and quality (HoGAN, 2017).

As far as social considerations, it is worth stressing that "finance performs two key functions beneficial to households and firms: risk management and inter-temporal consumption smoothing" (STEIN, 2010). These functions allow to reap benefits that range from managing day-to-day resources to taking advantage of investment opportunities, just to highlight the needs that are most often satisfied by banks and other financial institutions, though underbanked - and especially unbanked - market segments continue to be a source of serious concern, particularly in agriculture.

\section{Inclusive finance}

Their unmet needs act as a stimulus to aim at financial inclusion: it "means that individuals and enterprises can access and use a range of appropriate and responsibly provided financial services offered in a well-regulated environment" (FINANCIAL INCLUSION, n.d.); an interlinked approach rests upon financial resilience as the declared, feasible capacity to survive financial shocks and to obtain money for unexpected expenses (SOLARZ, 2017). Overall, it can be agreed on that "inclusive finance strives to enhance access to financial services for both individuals and micro-, small and medium-sized enterprises" (INCLUSIVE \& LOCAL FINANCE, n.d.), as a way to reduce poverty, tackle inequality and foster growth, thus unveiling the potential for improvement among smallholder farmers.

Actually, there is remarkable empirical evidence that supports a clear relationship between a wider recourse to finance and reduced income inequality and poverty. As such, financial inclusion can be said not only pro-growth but also pro-poor, which leads to deploy significant resources to the objective of inclusive rural transformation: it can be expected "to generate improved and more stable livelihoods for all rural people, including smallscale farmers, land-poor and landless workers, women and youth, marginalized ethnic groups and victims of disaster and conflict", as suggested by the International Fund for Agricultural Development (IFAD, 2016).

In developing countries, more than elsewhere, access to financial services is crucial to strengthen the financial sector, as well as to support the process of domestic resource mobilization, and the costs to people of being financially excluded should not be underestimated (PRABHAKAR, 2018): despite some criticism (MADER, 2017), an increasingly shared view aims at promoting a more inclusive financial system by "intensifying the depth of outreach and providing services to marginalized groups, especially women, reaching beyond conventional microcredit to the people at the bottom of the economic pyramid" (InClusive FinANCE, 2013). To this end, the array of most useful tools cover the extension of savings, credit, insurance and payment services that tend to involve a relatively small amount of money and hence do not usually attract banks. 


\section{Blended finance}

Focusing on the supply of these services, it comes natural to evoke microfinance institutions but even most traditional financial intermediaries can play a pivotal role by participating in the joint efforts that are requested. They justify the Global Partnership for Sustainable Development that has been proposed by setting the last of the SDGs, based on a spirit of strengthened global solidarity and on the needs of the most vulnerable: all countries, all stakeholders and all people are supposed to cooperate in order to mobilize and share knowledge, expertise, technology and financial resources; these inclusive partnerships are proposed as being "built upon principles and values, a shared vision and shared goals that place people and the planet at the centre" and should be developed "at the global, regional, national and local level" (GoAL 17).

A closer look at the agricultural sector reveals a noticeable involvement of international organizations - just like UN, FAO and IFAD - committed to ethical and global goals. No surprise: the World Bank has made clear that "agricultural growth remains central to poverty reduction, particularly in the poorest countries, where a large share of the population relies on agriculture for their livelihood" (WB, 2011); however, according to the "2030 Agenda", a lot of energies should be still devoted to "encourage and promote effective public, public-private and civil society partnerships, building on the experience and resource strategies of partnerships" (UN, 2015).

In sight of promoting blended finance - as a combination of official development assistance with other public resources, as well as private and philanthropic funds (PEREIRA, 2017) guidelines have been made available by the European Commission that specifically refer to public-private partnerships (PPPs) for a quite long time (EC, 2003). Valuable evidence concerning the recourse to them in agribusiness stems from a series of appraisals that FAO has undertaken since 2010 in Africa, Asia and Latin America: success stories have been recorded in several countries, including Pakistan, Indonesia, Thailand, Kenya, United Republic of Tanzania, Ghana, Nigeria (SLATER ET AL., 2016), and may provide precious guidance on how to partner effectively with the private sector in order to mobilize support for agribusiness development; lessons learned are likely to favor arrangements whereby "public and/or philanthropic inputs 'leverage' or catalyse a private investment that otherwise would not be made, creating positive development outcomes" (LONSDALE, 2016), with special consideration to be devoted to building PPPs for agricultural innovation (HARTWICH ET AL., 2008).

\section{Rural finance}

It may also prove rewarding to resort to market segmentation principles that allow to define rural finance as one of the subsets of the financial industry. This market segment comprises the full range of financial services needed or anyway used in rural areas by households and enterprises; such a broad definition includes loans, savings, insurance, payment and money transfer services, and can be usefully broken down by identifying at least three areas, namely agricultural finance, agricultural value chain finance and agricultural microfinance.

Agricultural finance consists of financing agricultural-related activities, such as input supply, production, distribution, wholesale, processing and marketing, whereas agricultural value chain finance is devoted to loans and other financial services flowing to and/or through the various links involved in the multi-facet processes from farms to consumers; finally, agricultural microfinance is aimed at the provision of financial services - such as small-sized loans and savings services - to poor and low income people, as well as to small-scale business operators. All in all, it seems relatively easy to conceptualize these 
notions but supply- and demand-side constraints continue to hinder the development of a dedicated financial industry (IFAD, 2009: 16), especially in developing countries.

On one hand, informal financial service providers dominate in rural communities, though there are major opportunities to improve the outreach of financial products through formal financial institutions; on the other hand, a compelling need is commonly shared - as a glocal co-opetitive challenge - for improving financial competence by furthering financial education and literacy, so as to empower smallholder families and small agri-businesses to make - and upgrade their - recourse to finance. Undoubtedly, expansion of rural financial services is likely to create a win-win scenario, thus helping to reduce poverty and to achieve sustainable growth, even where financial inclusion is by itself a tough task.

\section{CONCLUSIONS}

Nobody would deny that the primary sector - and truly modern agriculture in the first place - can favor the trend towards sustainable growth, in both developing and industrialized countries, to the benefit of present and future generations, in line with the generation pact; for instance, supporting arguments stem from projects that have been developed in sight of relying on biological processes, recycling as much as possible and expending minimal amounts of energy. In turn, finance is crucial to the pursuit of ambitious achievements along the pathway to sustainability, as suggested by recent initiatives directed to improving financial inclusion of smallholder farmers.

Anyway, much more attention should be paid to rural finance: it still looks like an emerging market segment in the financial industry, which by the way also faces sustainability issues. A case in point deals with the adoption of responsible lending principles, that imply - but are not limited to - an unquestionable attitude towards inclusive finance and prevention of over-indebtedness; in more general terms, responsible decisions by financial institutions can be expected to address the environmental and social impacts of their investment and particularly of their loans.

For the best results to be scored, synergies can be exploited by promoting blended finance, just like clusters that encompass industrial and technological districts specializing in agricultural commodities: building capacity, pursuing innovation and enriching knowledge sound like promising goals that Universities are likely to contribute to; further academic implications to be accounted for cover the discipline status of rural finance and the provision of financial education - even within the framework of lifelong learning especially to rural populations. A network of most relevant partners may help to jointly face the glocal co-opetitive challenges ahead and hopefully experience the increased joy of sharing success stories, instead of simply sharing pains to lessen them.

\section{REFERENCES}

Demirguc-Kunt, A., Klapper, L., Singer, D., Van Oudhusden, P., (2006): The Global Findex Database 2014 - Measuring Financial Inclusion around the World, April, World Bank Group, Washington, DC.

EC (2003): Guidelines for Successful Public-Private Partnerships, Brussels.

FAO (2014): Building a common vision for sustainable food and agriculture - Principles and approaches, Rome.

FINANCIAL INCLUSION (n.d.): http://www.uncdf.org/financial-inclusion [accessed March $13,2018]$. 
GOAL 17: Revitalize the global partnership for sustainable development (n.d.): http://www.un.org/sustainabledevelopment/globalpartnerships/ [accessed March 11, 2018]. Hartwich, F., Tola, J., Engler, A., GonzÁles, C., Ghezan, G., VÁzQuez-Alvarado, J. M. P., Silva, J. A., De Jesús EspinozA, J., Gottret, M. V. (2008): Building Public-Private Partnerships, International Food Policy Research Institute, Washington, DC.

Hogan, P. (2017): Introductory Speech at the $3^{\text {rd }}$ EU Fi-compass Conference on Financial Instruments for Agriculture and Rural Development under the EAFRD $-10^{\text {th }}$ October 2017, Paris, https:/ec.europa.eu/commission/commissioners/20142019/hogan/announcements/introductory-speech-3rd-eu-fi-compass-conference-financialinstruments-agriculture-and-rural_en [accessed March 1, 2018].

IFAD (2009): Rural Finance - Policy, August, Rome.

IFAD (2016): Rural Development Report 2016 - Fostering inclusive rural transformation, Rome.

INCLUSIVE \& LOCAL FINANCE (n.d.): http://www.un.org/esa/ffd/topics/inclusivefinance.html [accessed March 11, 2018].

InClusive Finance: Challenges AND Opportunities - The Rome Based AGencies' PERSPECTIVE (2013): https://maintenance.ifad.org/documents/10180/dbee93fc-ba84-42bdad7b-7890195b8a11, March 21 [accessed March 11, 2018].

LONSDALE, C. (2016): Aligning blended finance with the Busan principles of development effectiveness, discussion paper, October, Development Initiatives, Bristol, UK.

MADER, P. (2017): Contesting financial inclusion, October, https://www.researchgate.net/publication/320226228_Contesting_Financial_Inclusion [accessed January 22, 2018].

PEREIRA, J. (2017): Blended Finance, February, Oxfam, Oxford.

PRABHAKAR, R. (2018): "Financial Inclusion: A Tale of Two Literatures", Social Policy \& Society, Cambridge University Press, February 26, https://www.cambridge.org/core/journals/social-policy-and-society/firstview [accessed March 13, 2018]: 1-14.

Slater, R., Wiggins, S., Harman, L., Ulrichs, M., Scott, L., Knowles, M., Pozarny, P., Calcagnini, G. (2016): Strengthening coherence between agriculture and social protection - Synthesis of seven country case studies, FAO, Rome.

SOLARZ, M. (2017): "The Importance of the Reciprocity Principle for Financial Inclusion", Studia Oeconomica Posnaniensia, 5(6): 82-99.

SUSTAINABLE FINANCE (n.d.): https://ec.europa.eu/info/business-economy-euro/bankingand-finance/sustainable-finance_en [accessed March 14, 2018].

Stein, P. (2010): Inclusive Finance, May 21, World Bank Group, http://siteresources.worldbank.org/DEC/Resources/84797-

1275071905763/Inclusive_Finance-Stein.pdf [accessed February 20, 2018].

TAYLOR, M. (2018): "World's free plastic-free aisle opens in Netherlands supermarket", The Guardian, February 28, https:/www.theguardian.com/environment/2018/feb/28/worlds-firstplastic-free-aisle-opens-in-netherlands-supermarket [accessed March 1, 2018].

UN (2015): Transforming our world: the 2030 Agenda for Sustainable Development, Resolution 70/1, September 25, New York.

WB (2011): Growth and Productivity in Agriculture and Agribusiness - Evaluative Lessons from World Bank Group Experience, Washington, DC. 